\title{
THE USE OF SIMULATION IN THE MODEL OF CRISIS MANAGEMENT Michaela Jánošíková ${ }^{1}$, Maroš Lacinák ${ }^{2}$
}

\begin{abstract}
Safety as essential quality, needed in the development strategy of every city should be constantly improved by newest technologies. As currently used software and practices were studied, it can be seen that in Smart City concepts, technologies help with governing the city mainly in the field of obtaining, processing and providing information. Interconnection of many various information sources brings the possibility of storing all the information in one central data storage, instead of separated storages for every individual informational source. Taking the information from a central informational centre and their automatic, real-time visualization by simulation technologies can improve safety in the below described ways. By combining advantages of interconnectivity and simulation technologies, we aim to take advantage of their identified possibilities in order to enhance crisis management in all phases of its model. The period before crisis event occurrence consists of the phaseof prevention and the phase of crisis planning. Within the period after crisis event occurrence, there are phases of response and recovery. In this paper, we also present The Laboratory of Modelling and Simulation of Crisis Phenomena in Traffic, which is a part of the University Science Park of the University of Žilina. This laboratory disposes of program VR Forces ${ }^{\circledR}$, that is used in our research.
\end{abstract}

JEL Classification Numbers: H12, DOI: 10.12955/cbup.v7.1476

Keywords: Crisis Management, Model of Crisis Management, Simulation.

\section{Introduction}

Nowadays, new technological possibilities allow us to improve many areas of life by various innovative means. Such is the aim of a Smart City concept, which is trying to transform cities of today into futuristic places that use the most out of technological progress to improve the quality of life of citizens. One area of Smart Cities is also crisis management, where information technologies can be used in every phase of the Model of Crisis Management. Many authors usually use the term Crisis Management Cycle, but in the Slovak Republic the term Model of Crisis Management is used. In our article, we will advance according to the Model of Crisis Management in the Slovak Republic created by Šimák (2016), which is illustrated in Figure 1.

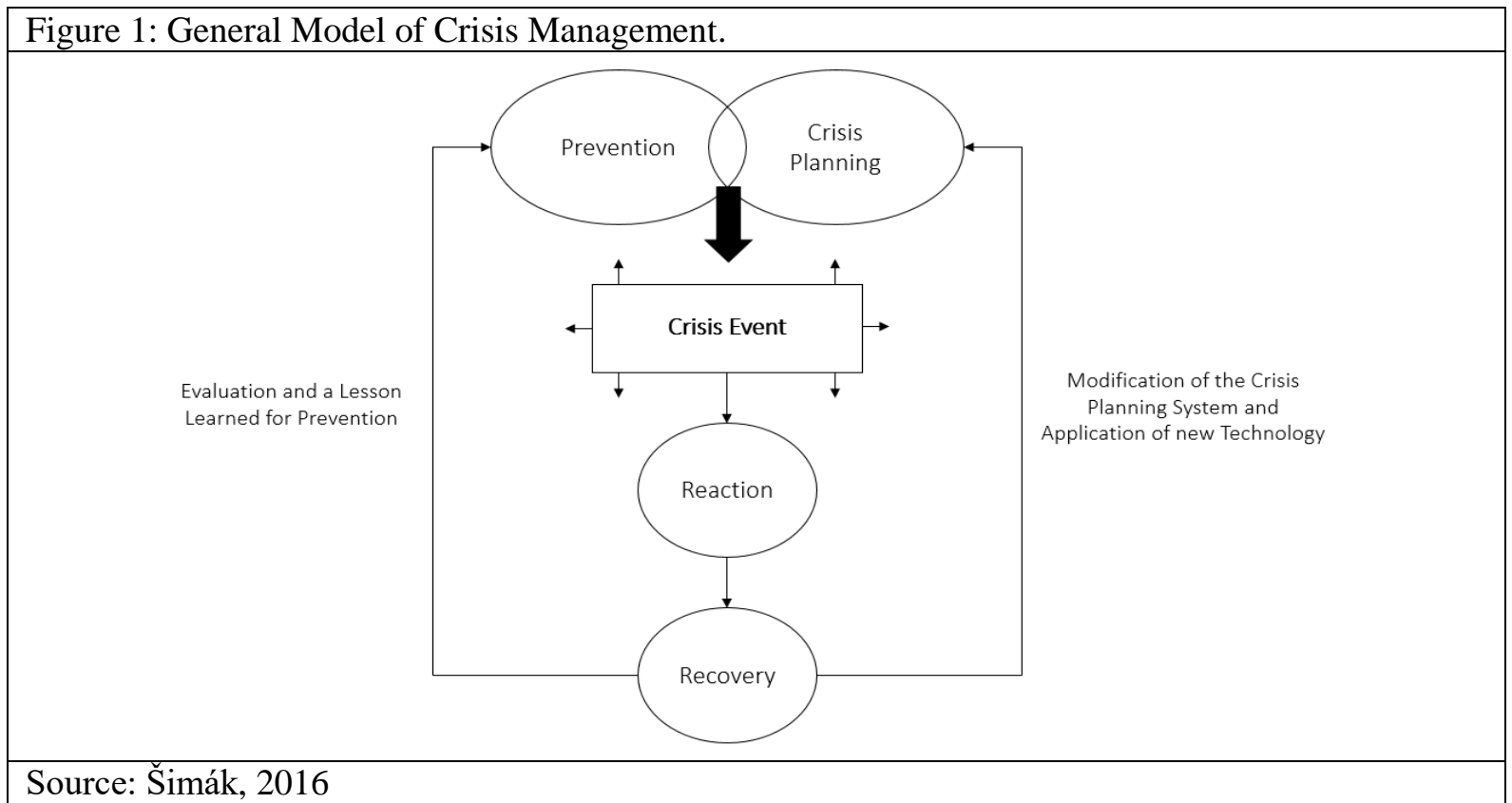

This model consists of four phases: prevention, crisis planning, reaction and recovery. In the light of crisis phenomena occurrence, these phases can be divided into two periods: phases before the occurrence - in the period of preparation, and after the occurrence of crisis phenomena -in the period of resolution.

\footnotetext{
${ }^{1}$ Department of Crisis Management, Faculty of Security Engineering, University of Žilina, Žilina, Slovakia, michaela.janosikova@fbi.uniza.sk

${ }^{2}$ Department of Crisis Management, Faculty of Security Engineering, University of Žilina, Žilina, Slovakia, maros.lacinak@fbi.uniza.sk
} 
The use of simulations as a supporting tool in different areas is on the rise. The big challenge is the use of simulations in the area of crisis management during the mentioned periods. Before the proposed design of such usage is described, it is necessary to define the term simulation and specify its basic types (Lovecek, 2016).

The simulation is the inclusion of the model in the system using appropriate inputs and tracking the relevant outputs (Walle, 2010). Rybár (2000) states that the simulation can be understood as a process associated with the use of an already created, prepared and validated model by a subject to solve a particular task.

Currently we recognize three basic types of simulation:

- virtual simulation - when simulated equipment in a simulated environment is used by real people

- live simulation - when simulated equipment is used by real people in the real world

- constructive simulation - when simulated equipment in a simulated environment is used by simulated people (Ristvej, 2016).

Rybár (2000) also mentions the fourth option, which is to combine the previous three types of simulations.

In the area of crisis management, it is possible to use all types of simulations: as training tools through virtual simulators, large live simulations of Integrated Rescue System, etc. In this paper we present a way to use the constructive simulation in the periods and phases of the Model of Crisis Management. The simulation program in use is the program VR-Forces ${ }^{\circledR}$, which is located at the Laboratory of Modelling and Simulation of Crisis Phenomena in Transport in the University Science Park of the University of Žilina.

The Laboratory of Modelling and Simulation of Crisis Phenomena in Transport enables the simulation of various types of crisis phenomena in different environments. Program VR-Forces ${ }^{\circledR}$ is a comprehensive simulation tool that allows us to simulate different situations in a real or fictional map background. It contains a vast set of features and models, in an attempt to provide as realistic an output as possible. VR-Forces ${ }^{\circledR}$ has a wide range of uses. It can be a tool for creating risk analysis, complex risk assessments in a diverse environment, verifying and assessing the competences and tasks of the state security system. It can be also tool for training the decision-making process of crisis management personnel, Integrated Rescue System and other element of crisis management (Ristvej, 2013). VRForces is described more closely in the article Possible Use of Geographical Information System within Crisis Management Simulations by Janosikova et al. (2018).

\section{Possibilities of the program VR-Forces® in the Model of Crisis Management}

Computer simulation that allows real-time simulation is a useful decision support tool. Based on real-world emergency data, it can provide better support in creating rescue strategies and planning the necessary resources by creating different scenarios. These can be differentiated by the number and the use of available forces and resources in different model situations. As every phase of crisis management model has different needs, we will cover each phase separately by identifying possible acquisitions of the simulation.

\section{The Period before Crisis Event Occurrence}

The period before crisis event occurrence consists of the phase of prevention and the phase of crisis planning. Both phases are exercised before the beginning of crisis phenomena and they partially intersect. That's why these phases are described together.

The phase of Prevention and the phase of Crisis Planning

In these phases, simulations can be used to predict the course and future of the crisis, to explore new responses to different types of events, to plan forces and resources, to create scenarios, to train and make decisions in crisis decision-making to improve the preparedness of crisis management personnel to solve crisis events. These activities are carried out in the phases of crisis planning as a tool for streamlining decision-making in the response phase.

One of the ways to use the simulation program VR-Forces ${ }^{\circledR}$ in the period before crisis event occurrence is to use it as a support tool during training and education. During preparation of training and exercise, the prevention phase data that will be incorporated into the prepared scenario needs to be used. The 
training and exercise is prepared and performed in the phase of crisis planning to support decisionmaking processes in the phase of response.

An important part of training and exercises using simulations is to create specific simulation scenarios in a computer program based on project documentation and testing their functionality. Although various types of crisis phenomena have common characteristics, each of them is individual. Therefore, scenarios of the same types of crisis phenomena will not always be identical and it will be necessary to create individual scenes to meet the required criteria. During the actual implementation of the training or exercise, its participants are shown individual model situations (scenarios). Based on the mediated information, their task is to properly respond to the situation.

Contributions are aimed to support the preparation of crisis management personnel and units of the Integrated Rescue System. The main objectives of this type of training are to improve the quality of decision-making processes of crisis managers, to improve their psychological resilience, to create model situations of crisis phenomena in different environments and evaluate the data to increase decision-making efficiency and human factor reliability.

\section{The Period after Crisis Event Occurrence}

After the crisis phenomena occurrence, the crisis management model enters into the resolution period. Its first phase is reaction, where we will again describe the use and potential contribution of the simulation. Afterwards we will similarly address the last phase of the model, that is the phase of recovery.

The Phase of Reaction

Our aim in the phase of reaction is to deliver a digital version of a city to crisis teams as a tool for decision making support, visualized in Figure 2.

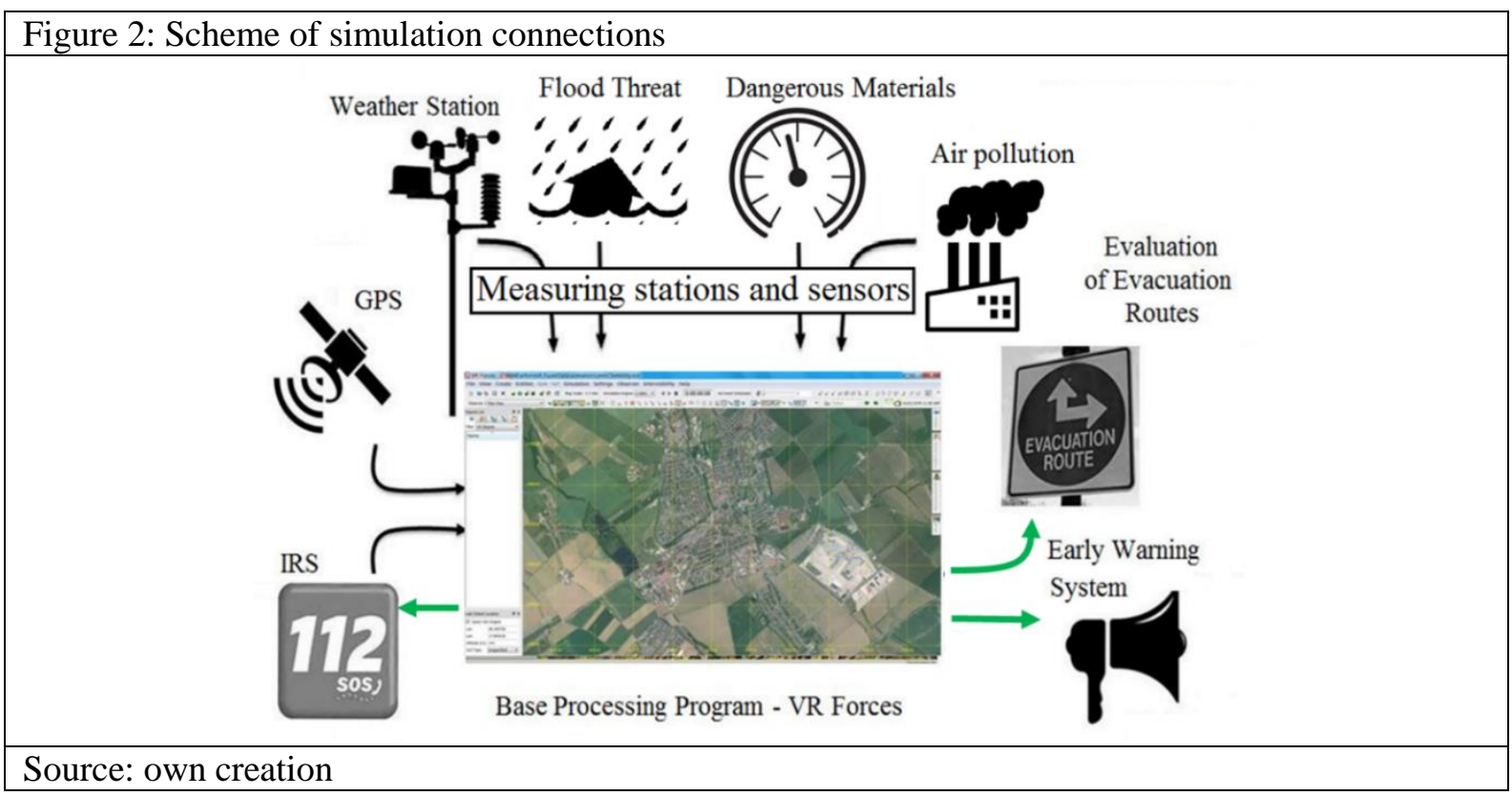

Simulation software in visualized smart connection with data sources from the environment has a potential to create a digital representation of the city and its surrounding, capturing the traffic situation, the occupancy and the movement of citizens in individual city areas.

As the scheme shows, the input for the simulation program should be provided by various measuring stations and sensors from the environment, that will together be able to provide as real a visualization of a current state of the city as possible. Actual weather conditions will be taken into account. Integrated rescue system units will be connected to this program as well, so that they can inform about reported accidents. The movement of Integrated Rescue System units will be monitored with GPS signal so the program will be able to pinpoint the location of all Integrated Rescue System vehicles for general overview. In return, Integrated Rescue System members will be able to access real-time visualization, provided by a simulation program through a small portable screen. Optional evacuation routes for endangered facilities in the given situation will be automatically calculated and sent to 
previously selected responsible personnel. Information provided by the simulation could be valuable for more precise assessment of the situation and it could be passed on to citizens through early warning system announcements.

To try out this possibility of use, an experiment is planned, where the VR Forces ${ }^{\circledR}$ system will be connected to the weather station and a sensor in laboratory, where controlled leakage of a dangerous substance will take place. The task for the simulation program will be to automatically take in and utilize this information from the sensor, locate the situation on a map background and visualize the spreading of the selected substance in the current weather, as if the leakage was not controlled.

By this visualization, we want to enhance the crisis management in the phase of reaction by the following contributions:

- faster and more precise information flow - information about changes in environment will be shown in digital visualization of the city directly from sensors, without any intermediary

- decision making support - by visualization of actual situation in real time to crisis teams and Integrated Rescue System units.

Contributions are aimed mainly to support the work of crisis management personnel and units of the Integrated Rescue System. Crisis management personnel will be able to more precisely anticipate the development of crisis phenomena because the program will be able to simulate development of the situation in an accelerated mode for the case, when the weather conditions will remain approximately the same. Members of Integrated Rescue System teams will have access to the visualization as well, allowing them to see the big picture on a small portable screen, with all relevant information at their disposal.

The Phase of Recovery

In the second phase of the resolving period, the simulation can be used as a tool for finding the most effective solution for reconstruction of public spaces and infrastructure. With the ability to create new maps and simulate the usual migration flow, it is possible to detect flaws in plans of reconstruction and more effective solutions might be found. This can be applied when there is need for a large-scale reconstruction after serious crisis phenomena, where we need to restore - and possibly improve previously built areas. Again, to get the most out of the simulation possibilities, the program needs to be connected to information sources that will provide an information base for understanding the life and needs of a city. This needs to be done before actual crisis phenomena will occur, because we need to understand the regular situation.

By understanding the regular life of a city, we want to enhance the crisis management in the phase of reconstruction through the following contributions:

- more effective planning of reconstruction

- testing of safety of planned reconstruction elements

- better service to the regular life of a city after reconstruction is done.

In this phase, the described use of the simulation will help mainly executives responsible for the development of the city and its safety.

\section{Conclusion}

Through the use of simulations, crisis management can be enhanced by the above described means. However, there are still questions to ask and problems to solve.

During the phase before crisis management occurrence it is possible to use constructive simulation as a support tool in trainings and exercises for crisis management personnel. Regularly organizing such trainings and exercises can greatly improve the preparedness of crisis management personnel to deal with crisis events, with focus on support and improvement of decision-making. One of the subjects to be explored and challenged for the future is the possible interconnection of such simulation technologies with systems that use rescue components.

In the phase of reaction, constructive simulation would surely provide support in the work of Integrated Rescue System members. The question is, if they will actually have the time to use their devices in stressful and hasty situations. For both - the phase of reaction and recovery alike - there is still room for improvement of the simulation program. The ability of simulating not only actions of Integrated Rescue System members and crisis phenomena development, but also physical attributes on buildings and 
infrastructure will be necessary to build a virtual projection of a city as close to its complexity as possible.

Creating such a virtual projection and the development of training policy for crisis management personnel are the main subjects of ongoing research. This research deals with the implementation of informational technologies into cities using the philosophies of Smart City and Safe City concepts. The main challenge is to make decision-making processes and communication processes in crisis management more effective. This is to be done through the implementation of simulation technologies into the process of resolving crisis phenomena and into the process of training for crisis management personnel. The current phase of research is focused on setting the course of crisis management personnel preparation with the use of simulations, as well as creating and preparing individual scenarios that will be tested in the next phase of the research.

Despite yet unsolved aspects, the Laboratory of Modelling and Simulation of Crisis Phenomena in Traffic has the potential to gradually bring all the possibilities to practice and so it is possible to enhance the crisis management in ways that will help all previously mentioned parties. But at the end of day, the main reason of all such development is to create better and safer places to live for all citizens.

\section{Acknowledgment}

This work was supported by the Internal Grant Scheme of Faculty of Security Engineering, University of Žilina from the grant No. IGP201805 Analysis and evaluation of available materials for training of crisis staff using simulation technologies.

\section{References}

Jánošíková, M., Ristvej, J., \& Lacinák, M. (2018). Possible use of Geographical Information System within Crisis Management Simulations. In: CBU International Conference Proceedings 2018 : Innovations in Science and Education : March 21-23, 2018, Prague, Czech Republic. Prague: CBU Research Institute. 216-220. ISBN 978-80-270-5037-6, https://www.researchgate.net/publication/328798052_POSSIBLE_USE_OF_A_GEOGRAPHICAL_INFORMATION_SYS TEM_WITHIN_CRISIS_MANAGEMENT_SIMULATIONS, DOI: https://dx.doi.org/10.12955/cbup.v6.1159.

Lovecek, T. et al. (2016). Currently required competencies of crisis and security managers and new tool for their acquirement - The eSEC portal, In: 13th IEEE International Conference on Emerging eLearning Technologies and Applications (ICETA 2015), Article Number: 7558492, https://ieeexplore.ieee.org/document/7558492, DOI: https://dx.doi.org/10.1109/ICETA.2015.7558492.

Ristvej, J. et al. (2013). Modelling, simulation and information systems as a tool to support decision-making process in crisis management. In: Modelling and Simulation 2013 - European Simulation and Modelling Conference, ESM 2013, EUROSIS. 71-76. ISBN 978-90-77381-79-3,

https://www.researchgate.net/publication/261985814_Modelling_simulation_and_information_systems_as_a_tool_to_suppor t_decision-making_process_in_crisis_management.

Ristvej, J., Ondrejka, R., Šimák, L., Loveček, T., Hollá, K., Lacinák, M., Šurinová, L., \& Jánošíková, M. (2016). Simulation Technologies in Risk Prevention within Crisis Management. In: ESM'2016 - Modelling and simulation 2016 : the European simulation and modelling conference 2016, October 26-28, 2016 Las Palmas, Gran Canaria, Spain. Ostend: EUROSIS-ETI, 2016. ISBN 978-90-77381-95-3.

Rybár, M. et al. (2000). Modelovanie a simulácie vo vojenstve [Modelling and simulation in the military]. Bratislava, Slovakia: Vydavatel'ská a informačná agentúra, Ministerstvo obrany Slovenskej republiky. 398 p. ISBN 80-88842-34-4.

Šimák L. (2016). Crisis Management in Public Administration. 2. edition. Žilina: University of Žilina, EDIS - UNIZA press, ISBN 978-80-554-1165-1.

Walle, van de, B. et al. (2010). Information Systems for Emergency Management. New York: ME. Sharpe, 2010, ISBN $978-$ 0-7656-2134-4, DOI: https://doi.org/10.4324/9781315703473. 